\title{
Redução e Substituição do Ácido Crômico na Etapa de Condicionamento de ABS para Metalização
}

\author{
Ana Paula Kurek, Noeli Sellin \\ Mestrado em Engenharia de Processos, Universidade da Região de Joinville, SC \\ Michael Gelsleichter \\ Departamento de Química Industrial, Universidade da Região de Joinville, SC
}

\begin{abstract}
Resumo: Na etapa de condicionamento de peças em acrilonitrila-butadieno-estireno (ABS), geralmente, são empregadas soluções sulfocrômicas, resultando na geração de efluentes altamente tóxicos e ambientalmente poluentes. Este trabalho apresenta resultados do estudo do emprego de soluçães condicionantes visando à redução e substituição do ácido crômico. O condicionamento das amostras foi realizado em banhos contendo soluções de ácido crômico e ácido sulfúrico, permanganato de potássio e ácido fosfórico, e ácido sulfúrico, ácido fosfórico e dicromato de potássio, variando-se concentração, tempo de imersão e temperatura. A morfologia e estrutura da superfície das amostras foram analisadas por microscopia eletrônica de varredura (MEV), rugosidade e espectroscopia no infravermelho (FITR/ATR) e a qualidade da adesão metálica após cromagem foi avaliada por inspeção visual, testes de adesão e de corrosão por exposição à névoa salina. Os resultados mostraram que o condicionamento químico ocasionou remoção dos componentes do ABS na superfície das amostras, provocando modificações como rugosidade e formação de poros, cavidades e reentrâncias, que influenciaram na adesão e foram dependentes da solução e das condições empregadas. O ácido crômico pode ser empregado em concentrações menores que a solução padrão $\left(400\right.$ g. $\left.\mathrm{L}^{-1}\right)$ e soluções isentas deste foram eficientes na modificação da superfície e adesão metálica.
\end{abstract}

Palavras-chave: Metalização, ABS, condicionamento, tecnologia mais limpa.

\section{Reduction and Replacement of Chromic Acid in Step-Conditioning of ABS for Metallization}

\begin{abstract}
In step-conditioning (etching) of acrylonitrile-butadiene-styrene (ABS) terpolymer, use is generally made of sulfuric/chromic acid solutions resulting in the generation of highly toxic, environmentally polluting waste. The present work reports the results of a study of reduction and replacement of chromic acid from the etching solution. The samples conditioning was carried out in baths containing solutions of chromic and sulfuric acids, potassium permanganate and phosphoric acid, and sulfuric acid, phosphoric acid and potassium dichromate, varying concentration, etching time and temperature. The morphology and structure of the samples surface were analyzed by scanning electron microscopy (SEM), roughness and infrared spectroscopy (FITR/ATR) and the adhesion quality of the metallized samples was evaluated by visual inspection, adhesion test and corrosion by a salt spray. The results show that chemical conditioning causes removal of ABS components of the samples surface, causing changes such as increased roughness and formation of pores and microcavities, which influenced the metallic adhesion and were dependent on the solution and the conditions employed. Chromic acid can be used in concentration smaller than 400 g.L.- and less aggressive solutions were effective in changing the surface and promoting metallic adhesion.
\end{abstract}

Keywords: Metallization, ABS, conditioning, cleaner technology.

\section{Introdução}

A deposição metálica em peças poliméricas é um tipo de recobrimento de superfície que tem como objetivo principal melhorar suas propriedades decorativas. Dentre estes materiais, o terpolímero acrilonitrila-butadieno-estireno (ABS) é um dos mais empregados para este fim, devido principalmente à sua estrutura, composição química e propriedades físicas e químicas, tais como, excelente tenacidade, boa estabilidade dimensional, boa processabilidade, resistência química e baixo custo ${ }^{[1]}$. Para uma adequada adesão da camada decorativa, a superfície do polímero precisa ser modificada, previamente à deposição metálica, por processos químicos e/ou físicos, dentre os quais se destacam: banho em soluções químicas, metalização a vácuo, plasma, foto-oxidação por ultravioleta, fotocatálise e jateamento de $\operatorname{areia}^{[2-4]}$. Estes processos, geralmente, ocasionam alterações na morfologia e estrutura da superfície do terpolímero por

Autor para correspondência: Ana Paula Kurek, Mestrado em Engenharia de Processos, Universidade da Região de Joinville - Univille, Campus Universitário s/n - Bom Retiro, Caixa Postal 246, CEP: 89219-905, Joinville, SC, Brasil.E-mail: anapkurek@gmail.com 
meio de aquecimento local, quebra de ligações químicas e formação de microcavidades com aumento na rugosidade e aspereza, que proporcionam maior interação metal-polímero e favorecem à adesão da camada metálica ${ }^{[5]}$. $\mathrm{O}$ processo mais empregado pelas indústrias galvânicas para a modificação da superfície de peças em ABS é por imersão delas em banho condicionador (etapa do pré-tratamento), composto por soluções sulfocrômicas de ácido crômico $\left(400\right.$ g.L $\left.\mathrm{L}^{-1}\right)$ e ácido sulfúrico (400 g. $\left.\mathrm{L}^{-1}\right)$. O tempo de condicionamento no banho, normalmente, é de 5 a 15 minutos, com temperatura na faixa de $60-65^{\circ} \mathrm{C}^{[6]}$. Neste processo, a superfície do ABS é quimicamente atacada, podendo ocorrer o desenvolvimento de poros e consequentemente, um aumento substancial da área superficial. Além disso, sítios hidrofílicos desenvolvem-se na superfície. Devido ao ABS apresentar duas fases distintas, uma oxidação diferenciada é esperada. A fase referente ao copolímero acrilonitrila-estireno oxida mais lentamente do que a do butadieno, por isso a superfície torna-se porosa devido à remoção dos domínios de butadieno ${ }^{[7]}$. Embora esta solução seja tecnicamente eficiente, nesta etapa, são gerados efluentes líquidos contendo cromo hexavalente $\left(\mathrm{Cr}^{+6}\right)$ em concentrações que são bastante prejudiciais à saúde humana e ao meio ambiente ${ }^{[8]}$. Em virtude da rigorosa legislação ambiental adotada em todo o mundo, o uso destes produtos químicos tóxicos deve ser limitado tanto quanto possível. Diante disto, este trabalho teve por objetivo avaliar o emprego de diferentes soluções para o banho condicionante, ambientalmente menos impactantes, ou seja, com menores concentrações e isentas de ácido crômico, e que garantam boas propriedades de adesão e resistência à corrosão nas peças de ABS metalizadas.

\section{Experimental}

\section{Preparação das amostras}

Foram utilizadas como amostras, peças produzidas por injeção de resina ABS da marca BASF, cedidas pela empresa CIPLA Indústria de Materiais de Construção S/A (Joinville - SC). As soluções do banho condicionador, bem como, suas concentrações e condições operacionais, foram definidas baseando-se em estudos de Colom et al..$^{[9]}$, Teixeira \& Santini ${ }^{[10]}$ e Naruskevicius et al. ${ }^{[11]}$ e por meio de planejamento fatorial. Para cada ensaio, a solução teste foi formulada com os reagentes e quantidades descritos na Tabela 1 e completada com água deionizada até volume final de $1000 \mathrm{~mL}$. Visando simular condições empregadas na indústria, os reagentes foram utilizados sem tratamento prévio e, em sua maioria, com grau de pureza comercial, indicado entre parênteses para cada solução na Tabela 1. As soluções foram testadas nas temperaturas de 50,60 e $70{ }^{\circ} \mathrm{C}$, sob agitação, e tempos de imersão de 5, 10 e 15 minutos, com exceção dos banhos 12,13 e 14, para os quais foram de 1, 3, 5 e 7 segundos. Após o condicionamento, as amostras foram enxaguadas em água corrente e submetidas às etapas convencionais empregadas no processo industrial para a deposição da camada metálica (neutralização, ativação, aceleração, deposição química de níquel, deposição eletrolítica de cobre, níquel e cromo).

\section{Avaliação da qualidade final das peças cromadas}

\section{Inspeção visual}

A avaliação da deposição da camada metálica foi realizada por inspeção visual em todas as amostras cromadas, conforme norma interna da empresa CIPLA (Plano de Inspeção de Peças Cromadas). Foram analisados somente defeitos provenientes da etapa do condicionamento, como a presença de bolhas, deposição incompleta da camada de níquel químico e camada metálica e peças danificadas. As amostras foram consideradas aprovadas quando não apresentaram esses defeitos.

\section{Teste de adesão}

O teste de adesão da camada depositada foi realizado segundo a norma DBL $8465^{[12]}$. A peça cromada foi fixada em um dispositivo e serrada manualmente, a partir do verso em direção ao revestimento, evitando descascamento nas superfícies de corte. Este teste foi realizado somente nas amostras aprovadas na inspeção visual.

\section{Teste de corrosão por exposição à névoa salina}

As amostras cromadas foram expostas em névoa de solução aquosa com aproximadamente $5 \%$ de cloreto de sódio, por um período de 72 horas (temperatura $-35{ }^{\circ} \mathrm{C}, \mathrm{pH}=7$ e pressão $=0,7 \mathrm{kgf} / \mathrm{cm}^{2}$ ), conforme a norma NBR $8094^{[13]}$, numa câmara "salt spray", marca Digmact. As amostras foram posicionadas de maneira que a solução escoasse, e ao final do ensaio, foram lavadas em água para remoção de resíduos da solução e posteriormente, foram avaliadas por inspeção visual. Este teste foi realizado apenas nas amostras aprovadas no teste de adesão.

\section{Análise da modificação da superfície das amostras}

\section{Microscopia eletrônica de varredura (MEV)}

A morfologia e estrutura da superfície das amostras antes e após o condicionamento foram analisadas por MEV utilizando-se um microanalisador de sonda eletrônica da marca Zeiss, modelo DSM 940A. As amostras foram previamente metalizadas com ouro a fim de se tornarem condutoras e posteriormente, suas superfícies foram registradas com ampliação de 1000 vezes, e tensão de $5 \mathrm{kV}$.

\section{Rugosidade}

A rugosidade da superfície das amostras antes e após condicionamento foi determinada utilizando-se um rugosímetro Surftest 211, marca Mitutoyo, série 178. As análises seguiram a norma NBR ISO $3274^{[14]}$. Foram determinadas a rugosidade média (Ra) e a amplitude total da rugosidade (Rz). Os valores obtidos são uma média de três leituras por amostra $($ erro $= \pm 0,02 \mu \mathrm{m})$. 
Tabela 1. Composição dos banhos condicionantes.

\begin{tabular}{|c|c|c|}
\hline Solução & Componentes & Quantidade (g.L $\left.\mathrm{L}^{-1}\right)$ \\
\hline \multirow[t]{2}{*}{1} & Ácido Crômico (a) $(99 \%)$ & 200 \\
\hline & Ácido Sulfúrico (b) $(96 \%)$ & 400 \\
\hline \multirow[t]{2}{*}{2} & Ácido Crômico (a) $(99 \%)$ & 250 \\
\hline & Ácido Sulfúrico ${ }^{(\mathrm{b})}(96 \%)$ & 400 \\
\hline \multirow[t]{2}{*}{3} & Ácido Crômico (a) $(99 \%)$ & 300 \\
\hline & Ácido Sulfúrico ${ }^{\text {(b) }}(96 \%)$ & 400 \\
\hline \multirow[t]{2}{*}{4} & Ácido Crômico (a) $(99 \%)$ & 350 \\
\hline & Ácido Sulfúrico (b) $(96 \%)$ & 400 \\
\hline 5 & Ácido Crômico (a) $(99 \%)$ & 400 \\
\hline (solução padrão) & Ácido Sulfúrico ${ }^{\text {(b) }}(96 \%)$ & 400 \\
\hline \multirow[t]{2}{*}{6} & Ácido Fosfórico ${ }^{\text {(b) }}(85 \%)$ & 1512 \\
\hline & Permanganato de Potássio ${ }^{(c)}(99 \%)$ & 7 \\
\hline \multirow[t]{2}{*}{7} & Ácido Fosfórico (b) $(85 \%)$ & 1512 \\
\hline & Permanganato de Potássio ${ }^{(c)}(99 \%)$ & 15 \\
\hline \multirow[t]{2}{*}{8} & Ácido Fosfórico (b) $(85 \%)$ & 1344 \\
\hline & Permanganato de Potássio ${ }^{(c)}(99 \%)$ & 7 \\
\hline \multirow[t]{2}{*}{9} & Ácido Fosfórico ${ }^{\text {(b) }}(85 \%)$ & 1344 \\
\hline & Permanganato de Potássio (c) $(99 \%)$ & 15 \\
\hline \multirow[t]{2}{*}{10} & Ácido Fosfórico ${ }^{(b)}(85 \%)$ & 1176 \\
\hline & Permanganato de Potássio ${ }^{(c)}(99 \%)$ & 7 \\
\hline \multirow[t]{2}{*}{11} & Ácido Fosfórico ${ }^{\text {(b) }}(85 \%)$ & 1176 \\
\hline & Permanganato de Potássio ${ }^{(c)}(99 \%)$ & 15 \\
\hline \multirow[t]{3}{*}{12} & Ácido Sulfúrico (b) $(96 \%)$ & 1623 \\
\hline & Ácido Fosfórico ${ }^{\text {(b) }}(85 \%)$ & 99 \\
\hline & Dicromato de Potássio ${ }^{(b)}(99 \%)$ & 17,6 \\
\hline \multirow[t]{3}{*}{13} & Ácido Sulfúrico (b) $(96 \%)$ & 1472 \\
\hline & Ácido Fosfórico (b) $(85 \%)$ & 237 \\
\hline & Dicromato de Potássio $^{(b)}(99 \%)$ & 17,6 \\
\hline \multirow[t]{3}{*}{14} & Ácido Sulfúrico ${ }^{\text {(b) }}(96 \%)$ & 1288 \\
\hline & Ácido Fosfórico ${ }^{\text {(b) }}(85 \%)$ & 405 \\
\hline & Dicromato de Potássio $^{(b)}(99 \%)$ & 17,6 \\
\hline
\end{tabular}

a) Ferreira Ind. Química; b) Bushle e Lepper; e c) Atotech do Brasil Galvanotécnica Ltda.

\section{ATR)}

Espectroscopia na região do infravermelho (FITR/

Para avaliação dos grupos químicos presentes nas amostras antes e após o condicionamento, foram obtidos espectros FITR/ATR por um espectrofotômetro SPECTRUM 2000 (Perkin Elmer) equipado com acessório para reflexão total atenuada (ATR), com cristal de seleneto de zinco (ZnSe) e ângulo de incidência de $45^{\circ}$. A faixa de análise foi de 4000 à $400 \mathrm{~cm}^{-1}$, resolução de $4 \mathrm{~cm}^{-1} \mathrm{e}$ um total de 10 varreduras (scans) por amostra. As interferências, como ruídos e correção de linha base dos espectros apresentados neste trabalho, foram minimizadas e corrigidas durante as varreduras utilizando FTIR Software-Spectrum for Windows.

\section{Resultados e Discussão}

Para avaliação da qualidade do acabamento cromado, foram consideradas aprovadas as amostras que apresentaram resultado positivo em todos os testes realizados (inspeção visual, adesão por corte com serra e corrosão) após a deposição metálica. A Figura 1a apresenta foto de uma amostra apro- vada em todos estes testes, sem a presença de defeitos, e as Figuras 1b, c apresentam fotos de amostras reprovadas, evidenciando a presença de defeitos provenientes do mau condicionamento, como: deposição incompleta e falta de adesão da camada metálica no teste de adesão por corte com serra. Os defeitos mostrados nestas fotos foram a base de discussão dos resultados apresentados a seguir. O teste de corrosão por exposição em névoa salina foi realizado somente nas amostras aprovadas nos testes de adesão e como não foi reprovada nenhuma amostra devido à corrosão, não foi possível apresentar o defeito por meio de foto.

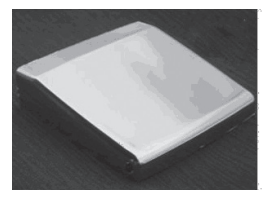

(a)

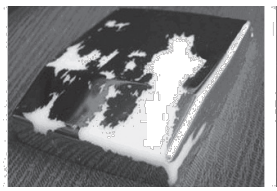

(b)

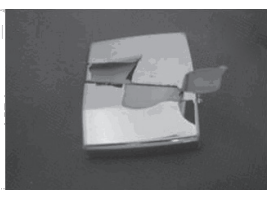

(c)
Figura 1. Fotos das amostras: a) aprovada; e amostras metalizadas com defeito: b) causado por deposição metálica incompleta; e c) causado por desplacamento da camada metálica no teste de corte com serra. 


\section{Solução de ácido crômico e ácido sulfúrico}

O emprego das soluções 1, 2, 3 e 4, visando reduzir a concentração do ácido crômico na etapa condicionante (geralmente, usada em torno de 400 g.L. ${ }^{-1}$, solução padrão 5, conforme Tabela 1), apresentou os seguintes resultados: um aumento na concentração de ácido crômico na solução acima inspeção visual e nos testes de aderência e corrosão por exposição à névoa salina. Entretanto, sob condições extremas de tempos de imersão e temperatura da solução (inferiores a 5 minutos $-50{ }^{\circ} \mathrm{C}$ e superiores a 15 minutos $-70{ }^{\circ} \mathrm{C}$ ), as amostras foram reprovadas, independente da concentração de ácido crômico na solução. O principal defeito observado foi o desplacamento, causado pela deposição incompleta da camada metálica. A Figura 2 apresenta MEV da superfície das amostras de ABS sem condicionamento e condicionadas em soluções com diferentes concentrações de ácido crômi-

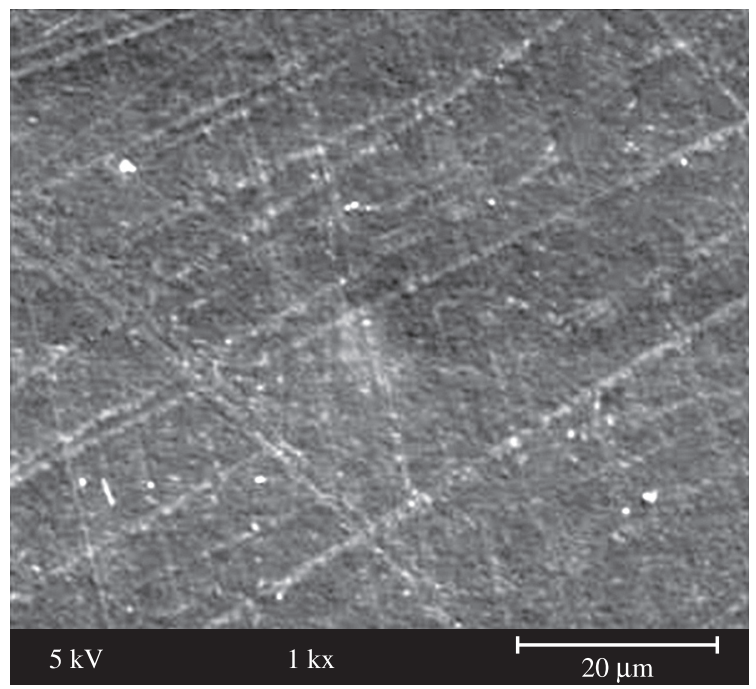

(a)

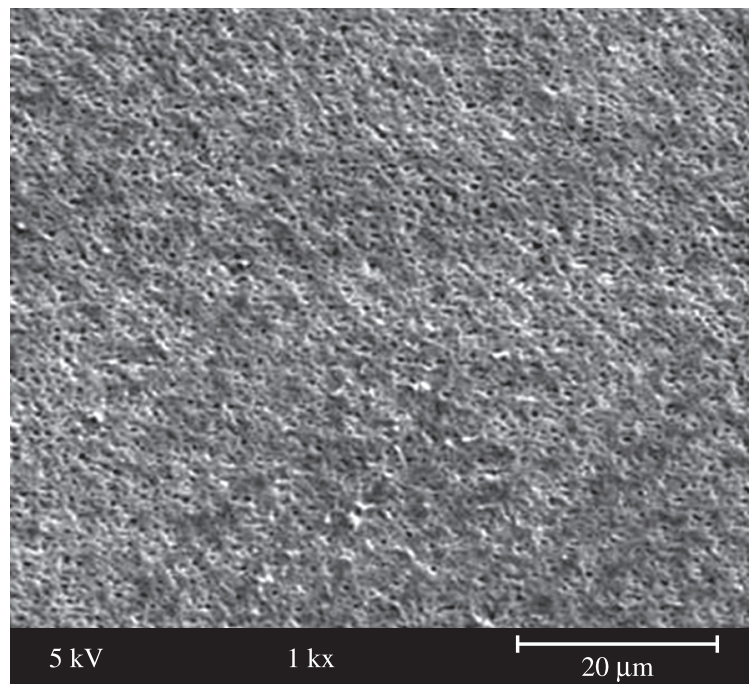

(b) de 250 g.L. $\mathrm{L}^{-1}$ ocasionou amostras com melhores resultados na

co, temperatura e tempo de imersão. Da Figura 2a, amostra sem condicionamento, observa-se uma superfície relativamente lisa, com baixa rugosidade, com $\mathrm{Ra}=0,05 \mu \mathrm{m}$ e $\mathrm{Rz}=0,67 \mu \mathrm{m}$. Nota-se ainda a presença de linhas ocasionadas provavelmente pelas imperfeições no molde de injeção. Das Figuras 2b, c, d, observa-se que o condicionamento com solução de ácidos crômico e sulfúrico ocasionou alterações significativas na superfície das amostras. Verifica-se a presença de microporos bem distribuídos, com diferentes tamanhos e formas, e rugosidade que são ausentes na amostra sem condicionamento. Um acréscimo na concentração de ácido crômico não ocasionou variação na rugosidade média, porém houve um aumento da amplitude total da rugosidade superficial, sendo $\mathrm{Ra}=0,11 \mu \mathrm{m}$ e $\mathrm{Rz}=0,87 \mu \mathrm{m}$ para a condição (b), $\mathrm{Ra}=0,07 \mu \mathrm{m}$ e $\mathrm{Rz}=0,97 \mu \mathrm{m}$ para a condição (c) e $\mathrm{Ra}=0,11 \mu \mathrm{m}$ e $\mathrm{Rz}=1,07 \mu \mathrm{m}$ para a condição (d). Segundo Villamizar et al. ${ }^{[15]}$, essas modificações contribuem para um

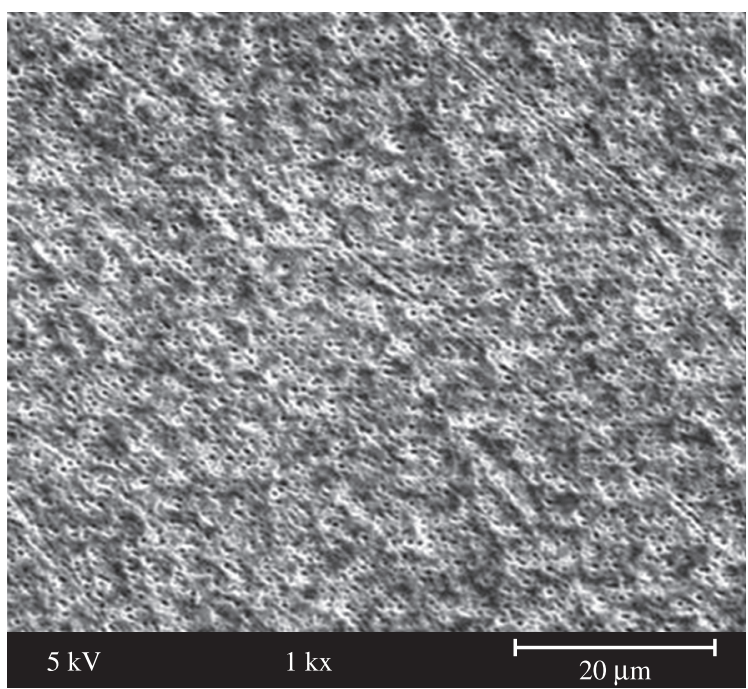

(c)

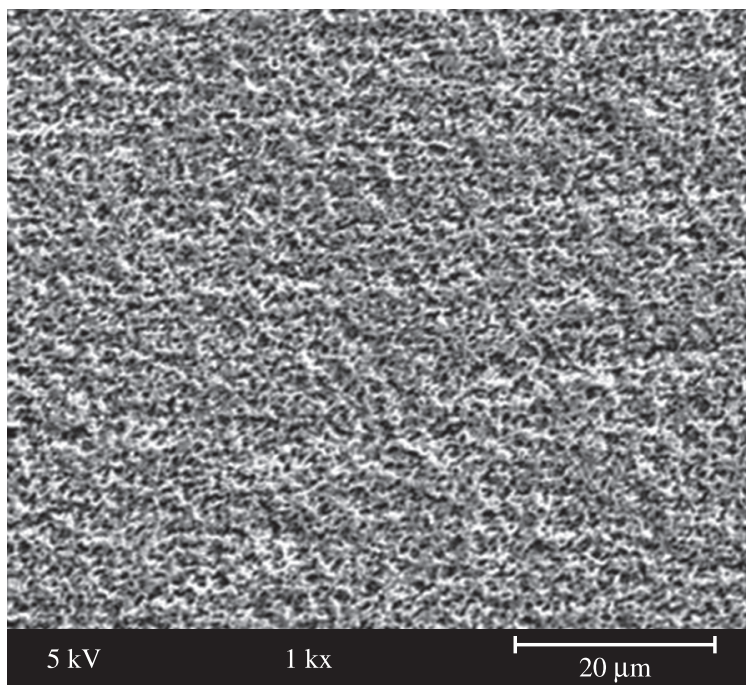

(d)

Figura 2. MEV das superfícies das amostras, a) sem condicionamento; condicionadas; b) $70{ }^{\circ} \mathrm{C}$ e 15 minutos na solução 1 com 200 g.L.- ${ }^{-1}$ c) $60{ }^{\circ} \mathrm{C}$ e 15 minutos na solução 2 com 250 g.. $\mathrm{L}^{-1}$; e d) $60^{\circ} \mathrm{C}$ e 10 minutos na solução padrão 5 com 400 g.L. ${ }^{-1}$. 


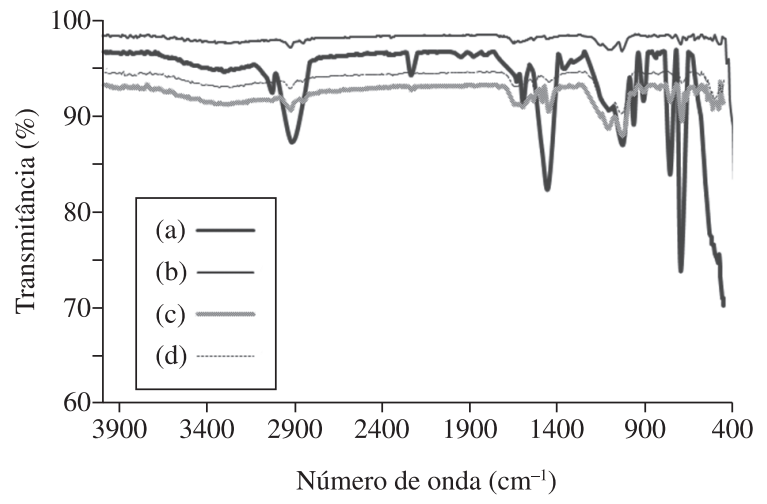

Figura 3. Espectros FTIR/ATR das amostras, a) sem condicionamento; e condicionadas com a solução 1 ; b) $70{ }^{\circ} \mathrm{C}$ e 15 minutos; c) $60{ }^{\circ} \mathrm{C}$ e 15 minutos; e d) com solução padrão $5,60^{\circ} \mathrm{C}$ e 10 minutos.

maior ancoramento mecânico do metal na superfície do ABS, favorecendo a adesão da camada metálica.

A Figura 3 apresenta espectros FTIR/ATR da superfície das amostras de ABS sem condicionamento e condicionadas em soluções contendo ácido crômico e ácido sulfúrico. Observa-se dos espectros, que a intensidade dos picos referentes à acrilonitrila $\left(\mathrm{em} 2260 \mathrm{~cm}^{-1}\right.$ ), butadieno (na região de 910 e $1000 \mathrm{~cm}^{-1}$ ), estireno (de 697 a $758 \mathrm{~cm}^{-1}$ ) e ligações C-H $\left(3000 \mathrm{~cm}^{-1}\right)$ diminui para as soluções de ácidos crômico e sulfúrico testadas. Essa diminuição é dependente do ataque provocado pela solução sob diferentes condições, sendo mais agressivo em temperaturas, tempos e concentrações maiores.

A aplicabilidade destas soluções contendo ácido crômico, em escala industrial, é possível, pois as amostras foram condicionadas em soluções com concentrações menores que as já usadas pelas indústrias de cromagem e com resultados positivos em relação à adesão metálica. Porém, mesmo reduzindo a concentração de ácido crômico nos banhos, deve-se atentar para as mesmas precauções na destinação dos efluentes gerados, sempre respeitando os limites estabelecidos pelos órgãos ambientais e também no manuseio das soluções em função da toxicidade ${ }^{[16]}$. Dos resultados, verifica-se que a morfologia alcançada na superfície da amostra após o condicionamento deve atingir um aspecto adequado para que possa haver deposição metálica satisfatória, ou seja, são necessários um tamanho e formato de poro e cavidades críticos para que isso ocorra, o que pode ser conseguido pelo ajuste das três variáveis nos banhos: concentração dos reagentes, tempo e temperatura. Para os banhos condicionantes com ácido crômico e ácido sulfúrico, condições extremas não foram adequadas à deposição metal-polímero. Superfícies com maior Rz, poros definidos e bem distribuídos apresentaram resultados mais satisfatórios.

\section{Solução de ácido fosfórico e permanganato de potássio}

Nos testes que visaram à substituição do ácido sulfúrico e do ácido crômico como agente oxidante pelo ácido fosfórico e permanganato de potássio foi constatado que apenas a solução 9 ocasionou a melhor deposição metálica, quando empregada a uma temperatura de $70{ }^{\circ} \mathrm{C}$ e tempo de imersão de 10 minutos. As amostras testadas sob as demais condições (soluções 6, 7, 8, 10 e 11) foram reprovadas.

A Figura 4 apresenta MEV das amostras condicionadas nas soluções 9 e 11 , a 70 e $60{ }^{\circ} \mathrm{C}$, respectivamente, e ambas por 10 minutos de imersão. A solução de ácido fosfórico e permanganato de potássio causaram alterações significativas na morfologia da superfície das amostras quando comparada com a da amostra sem condicionamento (Figura 2a). Não se observa poros com formatos bem definidos, mas cavidades ou reentrâncias com tamanhos visivelmente maiores que os da superfície das amostras condicionadas com solução sulfocrômica, mostradas nas micrografias da Figura 2 (amostras b, c e d). Foram encontrados para a amostra a) da Figura 4, valores de $\mathrm{Ra}=0,12 \mu \mathrm{m}$ e $\mathrm{Rz}=1,00 \mu \mathrm{m}$, semelhantes aos das amostras submetidas à solução sulfocrômica; e para a amos-

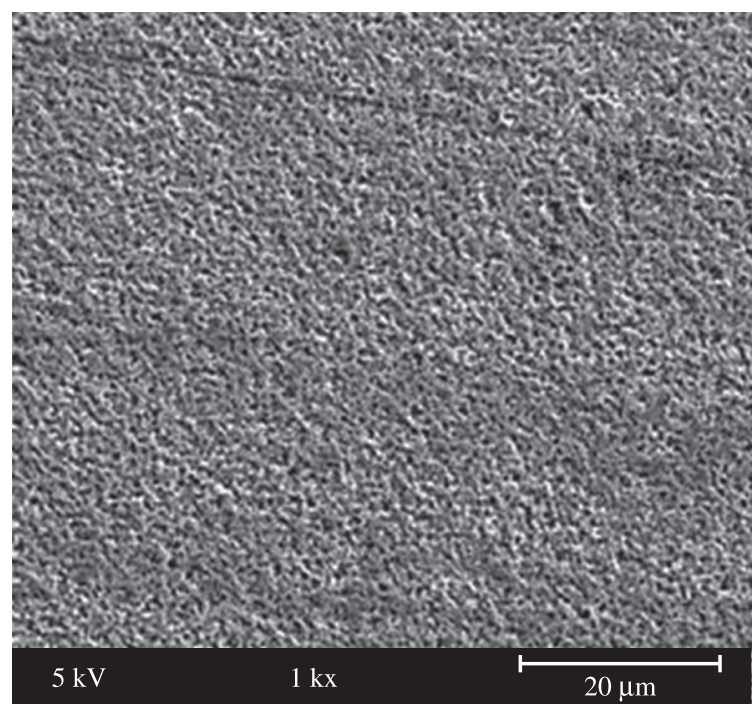

(a)

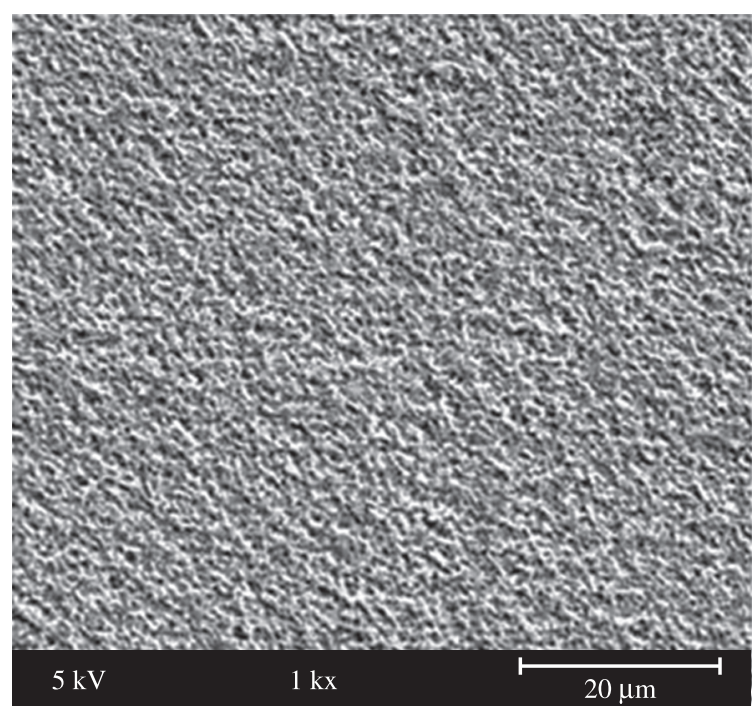

(b)

Figura 4. MEV da superfície das amostras condicionadas a: a) solução 9 , $70{ }^{\circ} \mathrm{C}$ e 10 minutos; e b) solução $11,60^{\circ} \mathrm{C}$ e 10 minutos. 


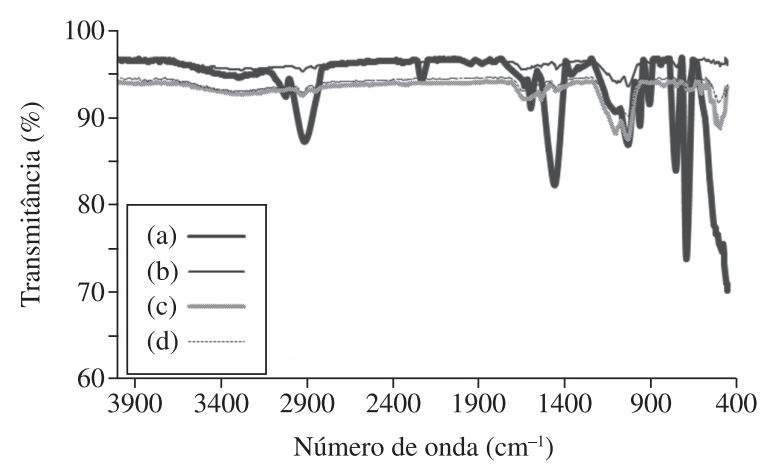

Figura 5. Espectros FTIR/ATR das amostras, a) sem condicionamento; e condicionadas a $70^{\circ} \mathrm{C}$ e 10 minutos; b) solução 9 ; c) solução 11 ; e d) solução padrão 5 (ácidos crômico/sulfúrico) a $60^{\circ} \mathrm{C}$ e 10 minutos.

tra; b) da Figura 4, valores de $\mathrm{Ra}=0,08 \mu \mathrm{m}$ e $\mathrm{Rz}=1,00 \mu \mathrm{m}$, sendo essa amostra reprovada devido ao baixo valor de Ra.

As amostras submetidas às demais soluções $(6,7,8,11)$, reprovadas em todos os testes, apresentaram morfologia da superfície bem semelhante à da amostra apresentada na Figura 4a, porém tiveram valores de Rz menores que $1 \mu \mathrm{m}$, não favorecendo a deposição metálica.

A Figura 5 apresenta os espectros FTIR/ATR da superfície das amostras de ABS sem condicionamento e condicionadas nas soluções 9 e 11 com ácido fosfórico e permanganato de potássio e na solução padrão, com solução sulfocrômica. Dos espectros, nota-se que a amostra condicionada na solução 9 apresentou maior remoção dos componentes do ABS na sua superfície do que a amostra submetida à solução 11, quando comparadas com a amostra sem condicionamento, e seu espectro se assemelha mais com o da amostra submetida à solução padrão 5. Este fato pode ser devido à solução 9 ser mais concentrada em ácido fosfórico e permanganato que as demais.

Observa-se ainda, que além dos poros formados pela remoção dos domínios de butadieno, há formação de cavidades, não visualizadas nas micrografias da Figura 2 (b, c e d), provavelmente pela maior remoção dos componentes da fase acrilonitrila-estireno, além do butadieno, que corrobora com os resultados dos espectros da Figura 5. Durante a realização dos testes, nas soluções contendo permanganato de potássio, mesmo aquecidas a $70{ }^{\circ} \mathrm{C}$, houve formação de material precipitado de difícil dissolução, e após o condicionamento, as amostras apresentaram superfície com coloração escura, marrom, que foi removida após a etapa de neutralização. Courduvelis et al. ${ }^{[6]}$, em suas patentes, explicam que soluções ácidas de permanganato de potássio são instáveis, tendo um curto período de vida e se decompõem rapidamente em dióxido de manganês, e que após o condicionamento, as amostras devem ser neutralizadas com um agente redutor que solubilize os resíduos de manganês formados na superfície e não prejudique as propriedades adesivas alcançadas.

\section{Solução de ácido sulfúrico, ácido fosfórico e dicromato de potássio}

Os resultados da avaliação das amostras submetidas aos banhos contendo ácido sulfúrico, ácido fosfórico e dicromato de potássio (soluções 12, 13 e 14), demonstraram que em tem- peratura mais baixa, de $50{ }^{\circ} \mathrm{C}$, as amostras foram aprovadas, independentemente do tempo de imersão, para soluções com maiores concentrações de ácido sulfúrico (solução 12). Quando esta foi reduzida, as amostras foram aprovadas somente quando submetidas a soluções com temperaturas maiores e tempos de imersão mais baixos. Comparando com os resultados apresentados anteriormente para os demais banhos, observa-se que neste caso, o ataque químico na superfície ocorre numa velocidade muito rápida, da ordem de segundos. Tempos de imersão maiores ocasionaram amarelecimento na superfície das amostras, o que pode estar relacionado a uma possível degradação química. É importante ressaltar que estas soluções também apresentam $\mathrm{Cr}^{+6}$, porém a concentração é bastante inferior ao banho condicionante padrão empregado pelas empresas de cromagem (solução 5, com 400 g.L.-1 de ácido crômico).

As Figuras 6a e b apresentam MEV da superfície das amostras condicionadas com a solução 12 , a $50^{\circ} \mathrm{C}$ e 1 segundo e a $60^{\circ} \mathrm{C}$ e 5 segundos, respectivamente. Observa-se que as alterações ocasionadas na morfologia da superfície da amostra submetida à solução de ácido sulfúrico, ácido fosfórico e dicromato de potássio são diferentes das apresentadas pelas amostras submetidas aos outros banhos condicionantes descritos anteriormente, mostrados nas Figuras 2b, c, d e 4a, b.

Verifica-se a presença de poucos poros e de ondulações, ao invés de cavidades e reentrâncias na superfície. As amostras submetidas às soluções a $50{ }^{\circ} \mathrm{C}$ e com concentração de ácido sulfúrico maior apresentaram valores de Ra e Rz mais elevados, da ordem de 0,12 e 1,40 $\mu \mathrm{m}$, respectivamente, sen-

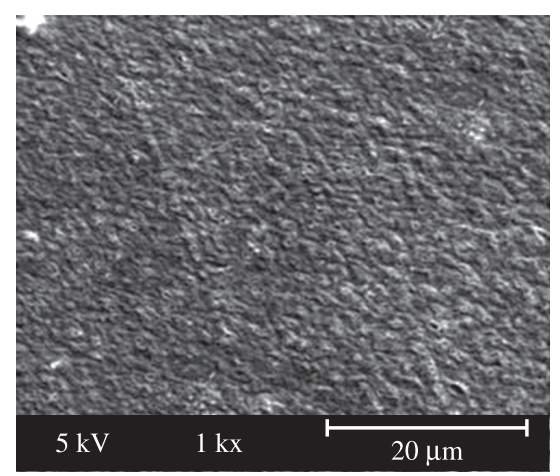

(a)

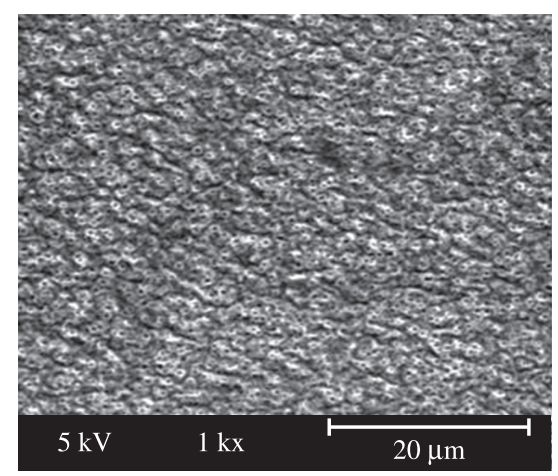

(b)

Figura 6. MEV da superfície das amostras condicionadas na solução 12 , a) $50{ }^{\circ} \mathrm{C}$ e 1 segundo; e b) $60{ }^{\circ} \mathrm{C}$ e 5 segundos. 


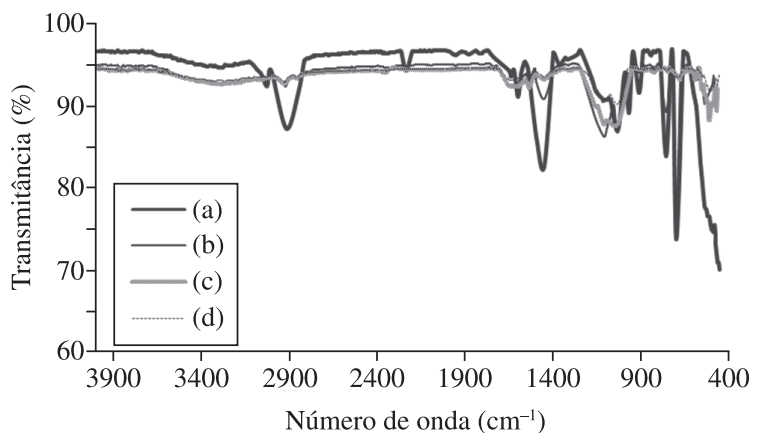

Figura 7. Espectros FTIR/ATR das amostras, a) sem condicionamento; condicionadas em solução 12 ; b) $50{ }^{\circ} \mathrm{C}$ e 1 segundos; c) $50{ }^{\circ} \mathrm{C}$ e 5 segundos; e d) solução padrão $5,60^{\circ} \mathrm{C}$ e 10 minutos.

do aprovadas. Um aumento simultâneo na temperatura e no tempo de imersão na solução causou aumento nas ondulações, porém houve um decréscimo significativo, principalmente em $\mathrm{Rz}$, para valores abaixo de $1 \mu \mathrm{m}$, dificultando o ancoramento mecânico do metal.

Na Figura 7 são mostrados os espectros FTIR/ATR das amostras sem condicionamento e condicionadas na solução 12 (1344 g. $\mathrm{L}^{-1}$ de ácido fosfórico e 135 g.L. ${ }^{-1}$ de persulfato de potássio), sob diferentes tempos de imersão, mantendo a mesma temperatura; e comparada com a solução padrão 5 contendo ácidos crômico/sulfúrico.

Em relação ao espectro da amostra sem condicionamento, as amostras condicionadas na solução 12 apresentaram diminuição da intensidade dos picos referentes aos componentes do ABS para as duas condições analisadas, e em relação ao da solução padrão 5 apresentaram comportamento bastante semelhante. Durante os ensaios, as amostras quando imersas por maiores tempos na solução condicionante contendo ácido sulfúrico, ácido fosfórico e dicromato de potássio apresentaram coloração escura. Conforme Sillos ${ }^{[17]}$, soluções mais concentradas de ácido sulfúrico têm mais efeito sobre a fase estirenoacrilonitrila, preferencialmente, sobre o estireno proveniente do anel benzênico pendente à cadeia principal, favorecendo o processo de degradação. Conforme apresentado, as soluções condicionantes contendo ácido sulfúrico, ácido fosfórico e dicromato de potássio necessitam de tempos muito baixos para provocarem o ataque químico à superfície das amostras, da ordem de segundos, quando comparadas com as demais soluções testadas. Apesar de ser um processo rápido, sua aplicabilidade no processo produtivo exige um controle rigoroso do tempo de imersão para que não haja degradação das amostras e perda na qualidade da adesão, o que pode ser minimizado e alcançado por meio de processos contínuos e automatizados.

\section{Conclusões}

As amostras submetidas às soluções condicionantes compostas por ácidos crômico/sulfúrico e ácidos sulfúrico/fosfórico mais dicromato de potássio obtiveram deposição do metal em toda sua superfície, apresentando os melhores resultados nos testes de adesão e corrosão se comparados com as amostras subme- tidas às soluções de permanganato de potássio e ácido fosfórico. No caso de soluções sulfocrômicas, conclui-se que não é necessária uma concentração de 400 g.L.-1 de ácido crômico, a redução é possível até uma concentração de 250 g.L.L perda na qualidade da adesão. As micrografias evidenciam as alterações na morfologia da superfície das amostras (formação de poros, microvales e reentrâncias), corroboradas pelos valores de rugosidade e pelos espectros FTIR/ATR, os quais indicaram a remoção dos três componentes presentes na estrutura do ABS. Estas alterações influenciaram diretamente na deposição metálica e mostraram ser dependentes da solução condicionante e das condições operacionais (concentração, temperatura e tempo) empregadas para cada uma. Soluções com menor grau de toxicidade e menos poluentes mostraram-se eficientes na promoção da adesão da camada metálica, indicando a possibilidade de substituição do ácido crômico no banho condicionador no processo de cromagem de peças em ABS. Em função das leis ambientais serem cada vez mais rigorosas em todo o mundo, métodos de tratamento menos poluentes, como os avaliados neste estudo, vem sendo empregados pelas empresas do setor.

\section{Agradecimentos}

À Empresa Cipla Indústria de Materiais de Construção S.A e FAP/UNIVILLE pela bolsa concedida.

\section{Referências Bibliográficas}

1. Maccaskie, J. E. - Plating on Plastics, may, (2006).

2. Bruyn, K.; Stappen, M. V.; Deurwaerder, H.; Rouxhet, L. \& Celis, J. P. - Surface and Coatings Technology, 163-164, p.710-715 (2003).

3. Kim, G. G.; Kang, J. A.; Kim, J. H.; Lee, K. \& Kim, S. J. - Scripta Materialia, 56, p.349-351 (2007).

4. Tang, X.; Cao, M.; Bi, C.; Yan, L. \& Zhang, B. - Materials Letters, 62, p.1089-1091 (2008).

5. Wang, G.; Li, N. \& Li, D. - Materials, 14, p.286 (2007).

6. Courduvelis, C. I. et al. - Plating on Plastics, Part B, p.212-227 (1983).

7. Mandich, N. V. \& Krulik, G. A. - Plat. Surf. Finishing, 80, p.68-73 (1993).

8. Kim. G. G.; Kang. J. A.; Kim. J. H.; Kim. J. S.; Lee. H. N. \& Kim. J. S. - Surface and Coatings Technology, 201, p.3761-3766 (2006).

9. Colom, X.; Massaneda, A. L.; Cañavate, F. J. \& Nogues, - Afinidad, Oct., 54, p.377-381 (1997).

10. Teixeira, L. A. C. \& Santini, M. C. - J. of Mat. Proc. Technology, 170, p.37-41 (2005).

11. Naruskevicius, L. et al. - "Process for metallizing a plastic surface". USA, United States Patent no. 6.712.948 B1, mar. (2004).

12. Daimler-Chrysler, DBL8465. Joinville (2002).

13. NBR 8094. "Material metálico revestido e não revestido - corrosão por exposição à névoa salina”. Método de ensaio. ABNT, Rio de Janeiro (1983).

14. NBR ISO 3274. "Rugosidade: método do perfil - Características nominais de instrumentos por contato". ABNT, Rio de Janeiro (1996).

15. Villamizar, C. A., Rojas, J. \& Frias, P. - Metal Finishing, mar. (1981).

16. Bayer, V. - "Estudo da extração de cromo hexavalente, pela técnica de membranas líquidas surfatantes, visando o tratamento de efluentes líquidos de curtumes", Dissertação de Mestrado, Universidade Federal de Minas Gerais, Brasil (2005).

17. Sillos, R. M. - "Curso de injeção e cromação de plásticos". SurTec do Brasil, São Paulo (2005).

Enviado: $12 / 11 / 08$

Reenviado: $22 / 06 / 09$

Aceito: $20 / 07 / 09$ 